\title{
Cutaneous ulcerations with systemic lupus erythematosus
}

\author{
Shinji Izuka MD, Yuko Takahashi MD PhD
}

Cite as: CMAJ 2021 November 15;193:E1734. doi: 10.1503/cmaj.210518

A

43-year-old woman presented to

our rheumatology clinic with a

2-month history of progressive, painful ulcerations after the appearance of purpura on the extensor surfaces of her lower legs (Figure 1A). She also had ulcerations and chilbains on her fingers (Figure 1B) and in her mouth. She had a fever, malar rash, alopecia and polyarthritis without nodular lesions or livedo reticularis. Ten years before presentation, she received a diagnosis of systemic lupus erythematosus (SLE) after presenting with polyarthritis. At that time, she had pancytopenia and hypocomplementemia, and tested positive for antibodies against double-stranded DNA. She was successfully treated with prednisone and had stabilized on a maintenance dose. However, 2 years before presentation she had stopped steroid treatment.

Laboratory findings showed lymphopenia, hypocomplementemia and antibodies against double-stranded DNA and cardiolipin, but the result of her lupus anticoagulant test was negative. Skin biopsy showed lymphocyte infiltration into the blood vessel wall, leukocytoclastic vasculitis with fibrinoid necrosis and panniculitis with calcium deposition. There was no evidence of thrombosis, pyoderma gangrenosum, infection, diabetic ulcer or neoplasm. Culture from the lesion was negative. Based on symptoms and pathology, we diagnosed cutaneous ulceration caused by lupus vasculitis. After treatment with prednisone $30 \mathrm{mg}$, followed by starting hydroxychloroquine $200 \mathrm{mg}$ and belimumab $200 \mathrm{mg} /$ week, the patient's ulcerations resolved over 6 months.

Although cutaneous involvement, such as malar and discoid rashes, is common in patients with SLE, ulceration is uncommon. ${ }^{1}$ In a retrospective study of 670 patients with SLE, 76 (11\%) patients developed vasculitis; of these, only 11 had ulcers or ischemic lesions. ${ }^{2}$ Typical histological findings include leukocytoclastic vasculitis with fibrinoid necrosis of the vessel wall and polymorphonuclear cell infiltration. ${ }^{1}$ Belimumab and hydroxychloroquine are recommended therapies for the cutaneous manifestations of $\mathrm{SLE}^{3}$ and are effective therapies for refractory cutaneous lupus erythematosus.

\section{References}

1. Shanmugam VK, Angra D, Rahimi H, et al. Vasculitic and autoimmune wounds. J Vasc Surg Venous Lymphat Disord 2017;5:280-92.

2. Ramos-Casals M, Nardi N, Lagrutta M, et al. Vasculitis in systemic lupus erythematosus: prevalence and clinical characteristics in 670 patients. Medicine (Baltimore) 2006;85:95-104.

3. Fanouriakis A, Kostopoulou M, Alunno A, et al. 2019 update of the EULAR recommendations for the management of systemic lupus erythematosus. Ann Rheum Dis 2019;78:736-45.

Competing interests: None declared.

This article has been peer reviewed.

The authors have obtained patient consent.

Affiliation: Division of Rheumatic Diseases, National Center for Global Health and Medicine, Tokyo, Japan

Content licence: This is an Open Access article distributed in accordance with the terms of the Creative Commons Attribution (CC BY-NCND 4.0) licence, which permits use, distribution and reproduction in any medium, provided that the original publication is properly cited, the use is noncommercial (i.e., research or educational use), and no modifications or adaptations are made. See: https://creativecommons.org/ licenses/by-nc-nd/4.0/

Acknowledgement: The authors thank Editage (www.editage.com) for English language editing.

Correspondence to: Shinji Izuka, izukashinji@gmail.com 